\title{
Endoderm Complexity in the Mouse Gastrula Is Revealed Through the Expression of Spink3
}

\author{
Hwee Ngee Goh,, Peter D. Rathjen,2 Mary Familari,, and Joy Rathjen ${ }^{1,2}$
}

\begin{abstract}
Endoderm formation in the mammalian embryo occurs first in the blastocyst, when the primitive endoderm and pluripotent cells resolve into separate lineages, and again during gastrulation, when the definitive endoderm progenitor population emerges from the primitive streak. The formation of the definitive endoderm can be modeled using pluripotent cell differentiation in culture. The differentiation of early primitive ectoderm-like (EPL) cells, a pluripotent cell population formed from embryonic stem (ES) cells, was used to identify and characterize definitive endoderm formation. Expression of serine peptidase inhibitor, Kazal type 3 (Spink3) was detected in EPL cellderived endoderm, and in a band of endoderm immediately distal to the embryonic-extra-embryonic boundary in pregastrula and gastrulating embryos. Later expression marked a region of endoderm separating the yolk sac from the developing gut. In the embryo, Spink3 expression marked a region of endoderm comprising the distal visceral endoderm, as determined by an endocytosis assay, and the proximal region of the definitive endoderm. This region was distinct from the more distal definitive endoderm population, marked by thyrotropin-releasing hormone (Trh). Endoderm expressing either Spink3 or Trh could be formed during EPL cell differentiation, and the prevalence of these populations could be influenced by culture medium and growth factor addition. Moreover, further differentiation suggested that the potential of these populations differed. These approaches have revealed an unexpected complexity in the definitive endoderm lineage, a complexity that will need to be accommodated in differentiation protocols to ensure the formation of the appropriate definitive endoderm progenitor in the future.
\end{abstract}

Key words: cellular biology; developmental biology; stem cells

\section{Introduction}

A S GASTRULATION IN THE MOUSE EMBRYO PROCEEDS, cells fated to form definitive endoderm emerge from the anterior primitive streak and intercalate with the overlying embryonic visceral endoderm. These cells expand anteriorly and laterally forming a layer of definitive endoderm that covers the embryonic region of the gastrula. ${ }^{1}$ The embryonic visceral endoderm, defined as visceral endoderm adjacent to the pluripotent primitive ectoderm, is dispersed and largely displaced into the extra-embryonic region, although scattered cells of visceral endodermal origin persist within the definitive endoderm. ${ }^{2}$ Molecularly, the formation of definitive endoderm during gastrulation is driven by high levels of Nodal signaling. ${ }^{3-6}$ Fate mapping studies have demonstrated that the definitive endoderm is regionalized, with distinct areas giving rise to specific segments of the gut tube and their associated organs. ${ }^{7-9}$ Unlike later derivatives of the definitive endoderm populations, such as the gut tube, which have been extensively divided into domains recognized by regionally specified genetic markers and with different developmental potential, ${ }^{10-12}$ developmentally defined regions of the definitive endoderm are poorly annotated, and there have been few regionally specified genetic markers identified. Recent advances have characterized a number of potential markers with restricted expression in the distal (Trh, Eya2, Dsp, Prss 12, ApoAIV, and 1600029D21Rik), ${ }^{13-15}$ and posterior (Klf5 and Epha2) ${ }^{15}$ definitive endoderm. Identification of additional gene markers that are regionally specified in the definitive endoderm will aid in the development of a comprehensive understanding of the definitive endoderm population. Furthermore, these genes will have application as markers to determine the molecular mechanisms that underpin the formation and development of definitive endoderm subtypes in vivo and in vitro.

It has been shown recently that the outer cell layer of embryoid bodies (EBs) derived from early primitive ectodermlike (EPL) cells comprises definitive endoderm similar to that formed in the E7.5 embryo ${ }^{16}$ and includes few, if any

\footnotetext{
${ }^{1}$ Department of Zoology, University of Melbourne, Victoria, Australia.

${ }^{2}$ The Menzies Research Institute Tasmania, University of Tasmania, Tasmania, Australia.
} 
cells of the visceral endoderm lineage. ${ }^{16,17}$ Potential definitive endoderm markers were identified from a microarray screen of EPL cell-derived EBs (EPLEBs) and characterized on in vitro models of development and mouse embryos. This approach identified the serine peptidase inhibitor, Kazal type 3 (Spink3) as a potential marker of the definitive endoderm. Expression of Spink3 was detected before gastrulation in a subset of embryonic visceral endoderm that demarcates the most proximal limits of the embryo. Expression was maintained in a band of definitive endoderm distal to the embryonic-extra-embryonic boundary. Later expression was detected in the border region separating the yolk sac and in the developing gut of headfold stage embryos. The expression of Spink3 is spatially distinct from the distal region of definitive endoderm marked by thyrotropin-releasing hormone (Trh), and overlaps with the most distal population of visceral endoderm as determined by an endocytosis assay. Spink3, therefore, marks a region of high cell complexity that forms the border between the embryonic and extra-embryonic endoderm and comprises both definitive endoderm, termed here proximal definitive endoderm, and visceral endoderm. Proximal definitive endoderm populations and definitive endoderm-expressing markers of more distal definitive endoderm populations could be detected in EPLEBs by gene expression and distinct differentiation potentials, and the prevalence of these populations could be influenced by culture medium and growth factor addition.

\section{Materials and Methods}

\section{Tissue culture}

Maintenance of ES cells. D3 ES cells ${ }^{18}$ were cultured in ES cell medium (Supplementary Table S1) as described previously. ${ }^{19}$ EPL cells were derived by culturing ES cells in medium supplemented with MEDII (50\% MEDII; Supplementary Table S1) as described. ${ }^{19}$ EBs and EPLEBs were formed from a single cell suspension of ES cells $\left(1 \times 10^{5}\right.$ cells $\left./ \mathrm{mL}\right)$ or EPL cells $\left(1.2 \times 10^{5}\right.$ cells $\left./ \mathrm{mL}\right)$, respectively, cultured in serum-containing medium (SCM, Supplementary Table S1) in bacterial grade plates (Interpath). EBs were divided 1:2 on day 2 of culture and medium replenished with SCM every 2 days. EBs formed and maintained in MEDII (EBMs) were formed from a single cell suspension of ES cells $\left(1 \times 10^{5}\right.$ cells $\left./ \mathrm{mL}\right)$ cultured in $50 \%$ MEDII in bacterial grade plates. Aggregates were divided 1:4 on day 2 of culture and further divided 1:2 on day 4. EBM culture medium was replenished on day 2 and daily from day 4; the medium used was 50\% MEDII on days 4-7 and with serumfree medium (SFM, Supplementary Table S1) on day 8. The day of seeding ES or EPL cells into bacterial dishes has been denoted as day 0 of differentiation. For gene expression analysis, EBs, EPLEBs, and EBMs were collected daily at a fixed time point for a period of 9 days. To investigate the effects of medium formulation and growth factors on definitive endoderm formation in EPLEBs, EPL cells were cultured in serum-containing medium (SCM) or medium supplemented with KnockOut $^{\mathrm{TM}}$ Serum Replacement (KOSRM, Supplementary Table S1) (Life Technologies) in bacterial grade plates to form EPLEBs. Activin A (30 ng/mL; R\&D Systems), Wnt3a (100 ng/mL; R\&D Systems), or BMP4 (10 ng/mL; R\&D Systems) were added after $24 \mathrm{~h}$ and maintained on the cells during daily medium replenishment until day 5. Control EPLEBs were refed with either SCM or KOSRM. To investigate the potential of EPL cell-derived definitive endoderm to form liver cell populations, EPLEBs were formed and cultured in SCM or KOSRM for 5 days; at this point, definitive endoderm was present in the aggregates. On day 5, EPLEBs were transferred to SCM, a medium shown to promote and support the formation of liver progenitors (H.N.G., personal observation), and cultured for a further 10 days with regular medium replenishment. This allowed the assessment of definitive endoderm differentiation in equivalent conditions.

Generation of the ALB-EGFP ES cell reporter line. An pALB-GFP construct (Gary Quinn, National Cancer Centre Research Institute, Japan), ${ }^{20}$ consisting of an enhanced green fluorescent protein (eGFP) reporter regulated by a $-9.3 \mathrm{~kb}$ to $-10.4 \mathrm{~kb}$ fragment of the albumin $(A l b)$ enhancer fused to a 300-bp minimal promoter sequence, was transfected into D3 ES cells using Lipofectamine 2000 (Life Technologies) according to the manufacturer's protocol. Transfected ES cells were selected using G418, DNA integration was confirmed with polymerase chain reaction (PCR), and a stably transfected clone was tested for the ability to up regulate eGFP during differentiation.

\section{Manipulation of mouse embryos}

Animal use was approved by the Animal Ethics Committee, Faculty of Science, University of Melbourne. Experimental work on mice was conducted in accordance with the Prevention of Cruelty to Animals Act 1986 and the Australian code of practice for the care and use of animals for scientific purposes, 7th edition (2004). Swiss mice were used throughout. Embryos were collected from pregnant mice on days 6.5, $7.5,8.5$, and 9.5 of gestation. Embryos to be used for wholemount in situ hybridization (WISH) were fixed in $4 \%$ paraformaldehyde in phosphate-buffered saline (PFA/PBS) (Sigma Aldrich) for $30 \mathrm{~min}$, washed in PBS, dehydrated through a graded methanol series, and stored in $100 \%$ methanol at $-20^{\circ} \mathrm{C}$. Embryos that were to be used for horseradish peroxidase (HRP) endocytosis assay were transferred into assay medium immediately after dissection.

\section{Gene expression analysis}

PCR analysis. Total RNA was extracted from aggregates using TRIzol ${ }^{\circledR}$ reagent (Life Technologies) according to the manufacturer's protocol. Traces of genomic DNA were removed with DNase 1 (Ambion), according to the manufacturer's protocol. cDNA was generated from RNA samples using Promega reagents. cDNA was diluted $1: 2$ and stored at $-20^{\circ} \mathrm{C}$. For reverse transcription (RT)-PCR, $1 \mu \mathrm{L}$ of cDNA was added to $10 \mu \mathrm{L}$ of $2 \times$ GoTaq Green Master mix (Promega), $8 \mu \mathrm{L}$ of nuclease-free water, and $1 \mu \mathrm{L}$ each of forward and reverse primers. Reactions were heated to $94^{\circ} \mathrm{C}$ for $1 \mathrm{~min}$ before repeated cycles of $94^{\circ} \mathrm{C}$ for $30 \mathrm{sec}, 30 \mathrm{sec}$ at an optimized annealing temperature (Supplementary Table S2), and $72^{\circ} \mathrm{C}$ for $30 \mathrm{sec}$ in a thermocycler (MJ Research). The number of cycles used for each primer set can be found in Supplementary Table S2. Ten microliters of each PCR amplification was analyzed by agarose gel electrophoresis and visualized with a Molecular Imager $^{\circledR}$ ChemiDoc $^{\mathrm{TM}}$ XRS Imaging System (BioRad). For quantitative (q)PCR, $1 \mu \mathrm{L}$ of cDNA and $200 \mathrm{nM}$ each of forward and reverse primers were added to $7.5 \mu \mathrm{L} 2 \times$ Absolute blue QPCR SYBR Green Mix (Thermo Scientific), and the 
reactions made to $15 \mu \mathrm{L}$ with nuclease-free water. Reactions were heated to $95^{\circ} \mathrm{C}$ for $15 \mathrm{~min}$ before cycling 40 times at $95^{\circ} \mathrm{C}$ for $15 \mathrm{sec}, 60^{\circ} \mathrm{C}$ for $15 \mathrm{sec}$, and $72^{\circ} \mathrm{C}$ for $30 \mathrm{sec}$ in a thermocycler (MJ Research Chromo 4). Gene expression values were normalized using $\beta$-actin. Mean normalized expression values of triplicates were obtained using the Q-Gene software package. $^{21,22}$ Relative fold change in expression level of each gene was calculated by dividing values of the treated samples with values from their respective control. Significance of data was determined using an unpaired two-tailed Student's $t$-test in Microsoft $^{\circledR}$ Excel software. Primer sequences and product sizes can be found in Supplementary Table S2. Primers were designed to span an intron-exon boundary.

WISH of embryos and cell aggregates. DNA templates for generating Amot, Spink3, Ttr, Trh, Tgfbli1, and Foxa2 riboprobes were constructed using the pGEM $^{\circledR}$-T Easy Vector Systems (Promega) according to the manufacturer's protocol. DNA fragments containing the gene of interest were transcribed from cDNA obtained from day 9 EBs by RT-PCR using gene-specific primers (Supplementary Table S2). Orientation of the DNA insert in the plasmid vector was determined by sequencing. Recombinant plasmids were linearized with NcoI (antisense template; NEB) and SalI (sense template; Promega). Antisense and sense riboprobes were synthesized with SP6 or T7 RNA polymerase (Promega) and DIG RNA labeling mix (Roche) as run-off transcripts from the linearized cDNA templates according to the manufacturer's protocol.

EPLEBs to be analyzed were fixed in $4 \%$ PFA/PBS for 30 min, dehydrated in a graded methanol series, and stored in $100 \%$ methanol at $-20^{\circ} \mathrm{C}$. WISH was performed as described by Rosen and Beddington ${ }^{23}$ with the following modifications. Prior to permeabilization, EPLEBs and embryos were treated with $6 \%$ hydrogen peroxide/phosphate buffered saline with $0.1 \%$ Tween 20 (PBT). Prehybridization and hybridization washes were performed at $65^{\circ} \mathrm{C}$. Following post hybridization washes, EPLEBs and embryos were blocked for $1 \mathrm{~h}$ in $10 \%$ heat-inactivated fetal calf serum in Tris-buffered saline with Tween (FCS/TBST) at room temperature. EPLEBs and embryos were then incubated at $4^{\circ} \mathrm{C}$ overnight in $1 \% \mathrm{FCS} /$ TBST containing anti-digoxigenin-AP antibody (1:2000) (Roche). For color development, EPLEBs and embryos were incubated in nitro blue tetrazolium and 5-bromo-4-chloro-3'indolyl-phosphate (Roche), as per the manufacturer's instructions until a signal was detected. EPLEBs and embryos were stored in $\mathrm{PBT}$ at $4^{\circ} \mathrm{C}$.

\section{HRP uptake assay (HRP endocytosis assay)}

Visceral endoderm in mouse embryos, EBs, and EPLEBs was labeled using a previously described endocytosis assay. ${ }^{16,24}$ Briefly, embryos or aggregates were incubated in Dulbecco's modified Eagle's medium containing $10 \%$ bovine serum albumin (Sigma Aldrich) and HRP (Type IV, $2 \mathrm{mg} / \mathrm{mL}$, Sigma Aldrich), at $37^{\circ} \mathrm{C}$ for $30 \mathrm{~min}$. Embryos or aggregates were fixed in $4 \%$ PFA/PBS for $30 \mathrm{~min}$, washed $5 \mathrm{~min}$ three times in PBS and incubated in 3,3'-diaminobenzidine (DAB; Sigma Aldrich) until a color change was observed. The reaction was stopped by rinsing the embryos or aggregates in PBS. Embryos or EPLEBs were dehydrated and stored in $100 \%$ methanol at $-20^{\circ} \mathrm{C}$. For colocalization of HRP uptake and definitive endoderm markers, EPLEBs and mouse embryos stained for HRP uptake assay were subsequently processed for WISH.

\section{Tissue processing, embedding, and sectioning}

EPLEBs and mouse embryos to be sectioned were postfixed in $4 \%$ PFA/PBS. EPLEBs were processed and embedded in paraffin wax in an automated tissue processor and sectioned at $8-\mu \mathrm{m}$ thickness. To facilitate processing, EPLEBs were sandwiched between supported nitrocellulose-1 paper (Life Technologies) and 1.5\% agar (Mpbio). Embryos were fixed in $4 \% \mathrm{PFA} / \mathrm{PBS}$, dehydrated in a series of progressively concentrated ethanol comprising 30\% (5 min), 50\% (5 min), $70 \%$ (5 min), 80\% (5 min, twice), 95\% (5 min, twice), and $100 \%$ ( $5 \mathrm{~min}$, three times) ethanol. They were then immersed in xylene ( $3 \mathrm{~min}$, twice, ChemSupply) and in paraffin wax at $60^{\circ} \mathrm{C}$ (30 min, three times). Embryos were embedded in the correct orientation in paraffin wax, sectioned at $8-\mu \mathrm{m}$ thickness. Images of embryos and aggregates were captured using an Olympus UC30 camera mounted on a Motic SMX-143 dissecting microscope. The same camera mounted on an Olympus BX50 upright microscope was used to capture sections of embryos and aggregates.

\section{Results}

The expression of putative definitive endoderm markers during ES cell differentiation in EBs, EPLEBs, and EBMs

A set of potential definitive endoderm markers was identified from a microarray analysis comparing EPLEBs on day 2 and 4 of differentiation. A group of genes up regulated on day 4 , and likely to be expressed by nascent mesoderm and nascent definitive endoderm ${ }^{16,17}$ (Supplementary Table S3), was further refined by eliminating genes that were previously reported to be expressed in the mesoderm and ectoderm to identify those genes most likely to be expressed in the definitive endoderm. A total of 10 genes were shortlisted for further analysis: Tgfb1i1, Tdo2, Amot, Spink3, Ttr, P2ry5, Sox 7, Map3k8, Sparc, and Lman2 (Supplementary Table S3). Three in vitro models of differentiation, EBs, EPLEBs, and EBMs, differing in the repertoire of cells formed, were analyzed by RT-PCR to characterize further the expression patterns of potential definitive endoderm markers (Fig. 1). EBs are widely documented to form cells representative of the three germ lineages and the extra-embryonic endoderm ${ }^{18,25-28}$; EPLEBs form derivatives of the primitive streak, mesoderm, and definitive endoderm and are deficient in ectodermal lineages and extraembryonic endoderm ${ }^{16,17}$; while differentiation in EBMs is restricted to the formation of the ectodermal lineages. ${ }^{29}$ Definitive endoderm markers would be expected to be expressed in EBs and EPLEBs, and not EBMs or pluripotent cells. Differentiation in EPLEBs is advanced in comparison to EBs, with the onset of molecular gastrulation occurring on day 2 compared to day $4,{ }^{16,17}$ such that the expression of prospective definitive endoderm markers expression would be expected to occur earlier, relative to day 0, in EPLEBs. Molecular gastrulation is used here to describe the events in EBs that recapitulate gastrulation in the embryo and can be recognized by the up-regulation of primitive streak markers such as T and Mixl1.

The up-regulation of $T$ expression, which marks the initiation of molecular gastrulation, is first seen on day 4 and 2 in EBs and EPLEBs, respectively (Fig. 1A, B). Like $T$, the onset of expression of the prospective definitive endoderm markers was detected approximately $48 \mathrm{~h}$ earlier in EPLEBs than in EBs, with the exception of Map3k8, Sparc, and 
A

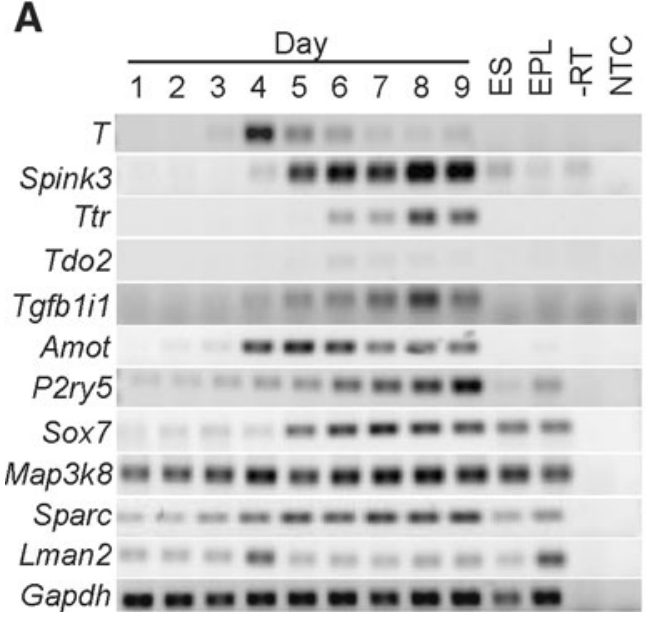

B

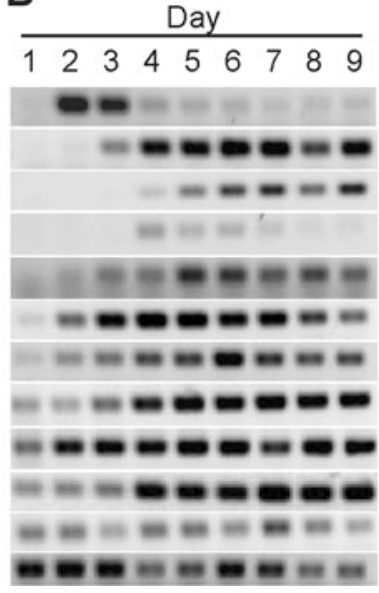

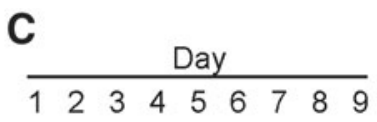

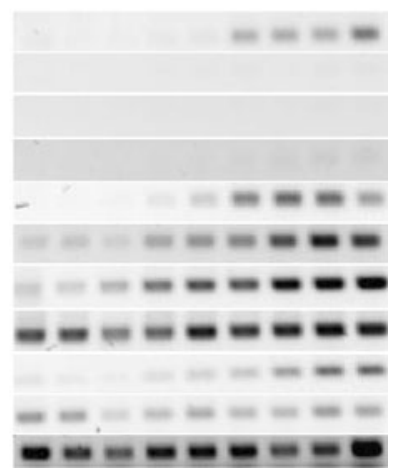

FIG. 1. Expression pattern of potential definitive endoderm markers in in vitro models of differentiation. Gene expression of potential definitive endoderm markers was analyzed in EBs (A), EPLEBs (B), and EBMs (C) by RT-PCR. Gapdh was used as a loading control. $n=3$, a representative result is shown. EB, embryoid body; EPLEBs, EPL cell-derived EBs; EBM, embryoid body cultured and maintained in MEDII; EPL, early primitive ectoderm-like cells cultured for 2 days; ES, embryonic stem cells cultured for 2 days; -RT, negative control in the absence of reverse transcriptase; NTC, no template control.

Lman2 (Fig. 1A, B). These gene products were detected in all populations analyzed. Expression of P2ry5 and Sox 7 was detected in EBs, EPLEBs, and EBMs; expression in EBMs suggests these genes were up-regulated in the ectoderm lineage (Fig. 1). Amot, Spink3, Tdo2, Tgfbli1, and Ttr were expressed in EBs and EPLEBs, and at reduced levels, if at all, in EBMs (Fig. 1C) and not in ES and EPL cells (Fig. 1A); these genes were selected for further analysis. P2ry5, Sox7, Map3k8, Sparc, and Lman2 were not pursued further.

\section{Location of cells expressing potential definitive endoderm markers in EPLEBS}

Previous characterization has shown that cells on the surface of EPLEBs on day 5 resemble definitive endoderm by gene expression (specifically by Sox17 expression), morphology, and endocytosis ability, while cells located internally express markers of mesoderm. ${ }^{16}$ The location of cells expressing Amot, Spink3, Tgfbli1, and Ttr in EPLEBs was determined by WISH (Fig. 2). Foxa2, a commonly used definitive endoderm marker, ${ }^{26,30}$ was included. Although often used as a marker of the definitive endoderm, Foxa 2 is expressed in the mesoderm as it forms in the embryo. ${ }^{30}$ Spink3 (Fig. 2A) and Ttr (Fig. 2B) were expressed specifically in a squamous layer of cells encapsulating the EPLEB, the cell layer that has been previously identified as definitive endoderm. ${ }^{16}$ Amot (Fig. 2C), Tgfblil (Fig. 2D), and Foxa2 (Fig. 2E) transcripts were detected in the squamous cells on the surface of EPLEBs and in the mesenchyme in the core of EPLEBs, demonstrating expression in the definitive endoderm and newly formed mesoderm. A satisfactory signal could not be obtained from EPLEBs analyzed for the expression of Tdo2 (data not shown).

\section{Location of cells expressing potential definitive endoderm markers in mouse embryos}

The location of cells expressing of Amot, Spink3, Tgfbli1, and $T t r$ was determined in mouse embryos.

Spink3 was detected in E6.5 embryos in a band of cells that extended posteriorly from the anterior proximal midline (Fig. 3A, B). Expression was restricted to cells located distal to the circumferential constriction that delineates the embryonic and extra-embryonic boundary of the embryo (Fig. 3A). The distal embryonic region of embryo at this developmental stage is encapsulated by squamous embryonic visceral endoderm, while the proximal extra-embryonic region is surrounded by cuboidal extra-embryonic visceral endoderm. ${ }^{31,32}$ Spink3 was expressed specifically by the embryonic visceral endoderm
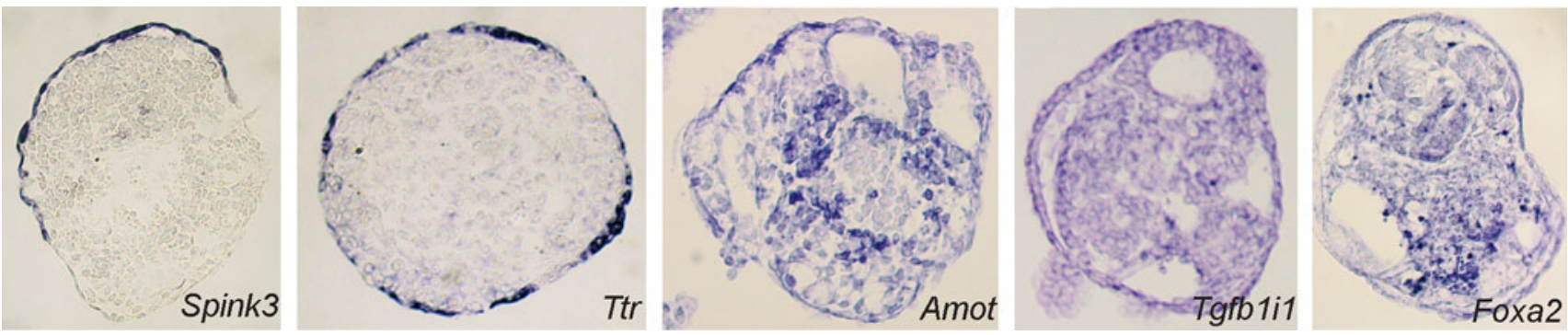

FIG. 2. Localization of mRNA transcripts of potential definitive endoderm markers in EPLEBs by wholemount in situ hybridization (WISH). The expression pattern of potential definitive endoderm markers was analyzed in day 5 EPLEBs. Foxa2 was included in the analysis as a positive control. Representative $8 \mu \mathrm{m}$ sections are shown. 


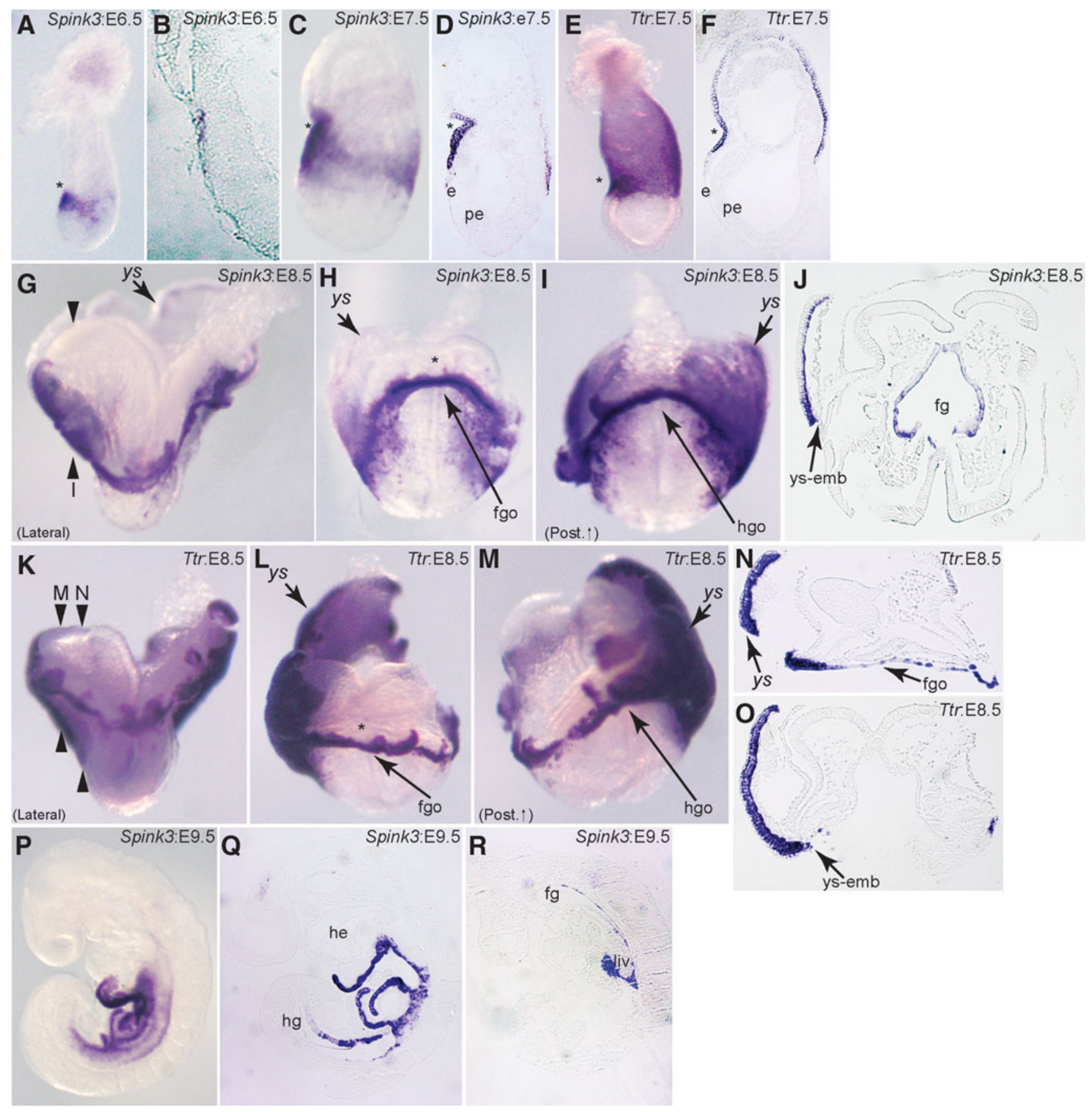

FIG. 3. Spink3 and Ttr expression in E6.5 to E9.5 mouse embryos. (A, B) Expression of Spink3 in an E6.5 mouse embryo by WISH, shown in wholemount and sagittal section. The position of the embryonic and extra-embryonic boundary in the anterior of the embryo is marked by an asterisk (*). Expression of Spink3 (C, D) and Ttr (E, F) in wholemount E7.5 mouse embryos $(\mathbf{C}, \mathbf{E})$ and sagittal sections $(\mathbf{D}, \mathbf{F})$. The position of the anterior of the embryo is marked by an asterisk $(*)$. Lateral $(\mathbf{G})$, frontal $(\mathbf{H})$, and rear (I) views of an E8.5 embryo stained for Spink3. The yolk sac on one side of the embryo has been removed. Transverse section ( $\mathbf{J}$ ) of the cranial region of the embryo showed expression of Spink3 in the walls of the foregut (fg) and in the yolk sac-embryo boundary (ys-emb; arrow). The position of the anterior of the embryo is marked by an asterisk (*) in H. Expression of Ttr in an E8.5 mouse embryo showing lateral (K), frontal (L), and rear (M) views and in transverse sections of the anterior region of the embryo (N, O). Expression of Spink3 in an E9.5 embryo, as shown by WISH (P), details of expression can be seen in sagittal (Q) and parasagittal (R) sections. fg, foregut; fgo, foregut opening; he, heart; hg, hindgut; hgo, hindgut opening; liv, liver anlage; Post, posterior; ys, yolk sac; ys-emb, yolk sac-embryo boundary. 
(Fig. 3B). In the E7.5 embryo Spink3 expression was detected in a ring of cells distal to the embryonic-extra-embryonic boundary (Fig. 3C). Sagittal sections of the embryo show Spink3 specifically expressed in the proximal definitive endoderm of the gastrulating embryo, with stronger expression in the anterior region (Fig. 3D). At E8.5 (four somites) Spink3 was predominantly detected along the boundary of the yolk sac and the embryonic embryo and in the lip of the foregut and hindgut opening (Fig. 3G-I). Expression of Spink3 was also detected in the lateral walls of the exposed regions of the foregut and hindgut. Yolk sac on the left side of the embryo was removed to allow visualization of the remaining parts of the embryo (Fig. 3G). Transverse sections of the anterior region of the embryo showed Spink3 expression in the walls of the foregut opening and in the yolk sac-embryo boundary (Fig. 3J). The expression of Spink3 diminishes proximally in the yolk sac. At a more advanced stage of development (eight-somite stage), Spink3 was detected in the ventral wall and rim of the closing gut (Supplementary Fig. S1). By E9.5 Spink3 was detected in the midgut and the rostral part of the hindgut (Fig. 3P-R).

Consistent with previous studies, ${ }^{2}$ Ttr mRNA transcripts were detected in the extra-embryonic visceral endoderm and in the proximal definitive endoderm of an E7.5 mouse embryo (Fig. 3E, F). Sagittal section of the embryo showed that $T t r$ is specifically expressed in the extra-embryonic visceral endoderm and the proximal definitive endoderm. At E8.5 (approximately four-somite stage), Ttr expression was detected in the yolk sac, lip of the foregut opening, and hindgut opening (Fig. 3K-M). Yolk sac on the left side of the embryo was removed to allow visualization of the embryo (Fig. 3J), which appeared to be unstained. Transverse sections of the anterior region of the embryo showed that Ttr is specifically expressed in the yolk sac and the lip of the foregut opening (Fig. 3N, O).

The expression of Amot and Tgfblil was determined in E7.5 (Amot) and E8.5 (Amot and Tgfbli1) embryos. Amot expression was detected throughout the endoderm with the exception of endoderm covering the anterior midline (Supplementary Fig. S2A, B, C). This pattern was broader than that seen previously, but was consistent in expression and was detected in both the extra-embryonic visceral endoderm and definitive endoderm of the embryo. ${ }^{15,33}$ By E8.5, Amot-expressing cells were detected in the lip of the foregut opening and in the allantois, derivatives of the definitive endoderm, and extra-embryonic mesoderm respectively (Supplementary Fig. S2D). In E8.5 mouse embryos Tgfblil expression was detected in the heart anlage, mid-dorsal region (Supplementary Fig. S2E), somites (Supplementary Fig. S2F) and the lip of the foregut opening (Supplementary Fig. S2G). The expression of these genes in derivatives of the endoderm and mesoderm is consistent with the detection of these genes in both lineages in EPLEBs.

\section{Analysis of the endoderm populations reveals a region of high cell complexity at the border between the embryonic and the extra-embryonic tissues in E7.5 embryos}

Disparity in endocytotic capabilities of definitive endoderm and visceral endoderm allows these two cell types to be distinguished in mouse embryos using a colormetric endocytosis assay. ${ }^{13,24,34-36}$ An HRP endocytosis assay was per- formed on freshly dissected E7.5 mouse embryos. DAB ${ }^{+}$ visceral endoderm was localized in the extra-embryonic region and in the most proximal domain of the embryonic region (Fig. 4A). Subsequent staining by WISH demonstrated that Spink3 is expressed in cells in the proximal domain of the embryonic region, below the amnion and overlapping with the region of HRP uptake (Fig. 4B). Sagittal (Fig. 4C, D) and coronal (Fig. 4E, F) sections showed two populations of Spink3 ${ }^{+}$cells. Spink3 ${ }^{+} \mathrm{DAB}^{+}$visceral endoderm was detected in the anterior, posterior, and lateral parts of the embryonic region beneath the amnion. Spink $3^{+} \mathrm{DAB}^{-}$definitive endoderm was detected subjacent to the $\operatorname{Spink} 3^{+} \mathrm{DAB}^{+}$visceral endoderm in the anterior, lateral, and posterior embryonic region. Spink $3^{-} \mathrm{DAB}^{+}$visceral endoderm was confined to the extra-embryonic region above the amnion.

Trh has been identified as a marker of the definitive endoderm in the distal most domain of embryo. ${ }^{13}$ Embryos processed by HRP uptake assay to show endocytosis and identify the visceral endoderm were stained to locate the expression of Trhexpressing cells by WISH. Trh expression and DAB-staining were mutually exclusive, and $T r h^{+}$cells were not detected in the proximal region of the embryo (Fig. 4G-K), suggesting that $\operatorname{Tr} h^{+}$cells are likely to be Spink $3^{-}$.

Double staining E7.5 mouse embryos by HRP endocytosis assay and Ttr WISH detected Ttr expression in the extra-embryonic visceral endoderm, above the amnion, and in the proximal endoderm below the amnion (Fig. 4L). Tissue sectioning revealed an overlap in DAB staining and Ttr expression in the extra-embryonic visceral endoderm (Fig. 4M-P). A population of $\mathrm{Ttr}^{+} \mathrm{DAB}^{-}$endoderm was, however, detected in the endoderm located distally to the amnion.

Analysis of endoderm marker expression pattern has revealed the presence of multiple endoderm populations within the embryonic region of the gastrulating embryo. To understand the populations that are formed during pluripotent cell differentiation, day 5 EPLEBs were double-stained by HRP endocytosis uptake assay and Spink3, Trh, or Ttr WISH (Fig. 5). As expected, the number of EPLEBs containing cells capable of endocytosis, indicating the presence of visceral endoderm, was low. ${ }^{16,17}$ Spink3 and Trh expression was detected in a layer of squamous cells on the surface of EPLEBs and the expression of these genes and HRP endocytosis was mutually exclusive (Fig. 5A, C, D, F). The majority of cells that expressed Ttr did not endocytose HRP, but cells capable of endocytosis did express Ttr as expected (Fig. 5E).

\section{Enrichment of distal and proximal definitive endoderm in EPLEBs}

Analysis of the embryo suggests the formation of at least two populations of definitive endoderm, a proximal population that expresses Spink3 and Ttr and a distal population that expresses Trh. Both populations can be detected on EPLEBs. The prevalence of these populations was determined by analyzing the relative transcript levels of Spink3, Ttr, Trh, and Eya 2 in EPLEBs cultured in KOSRM or SCM by qPCR (Fig. 6A). Eyes absent 2 homolog (Eya2) is an additional marker of the distal definitive endoderm with an expression pattern similar to that of $T r h .{ }^{14}$ Spink3 and Ttr expression was significantly higher in EPLEBs that were cultured in SCM compared to those that were cultured in KOSRM. In contrast, expression levels of Trh and Eya2 were significantly 

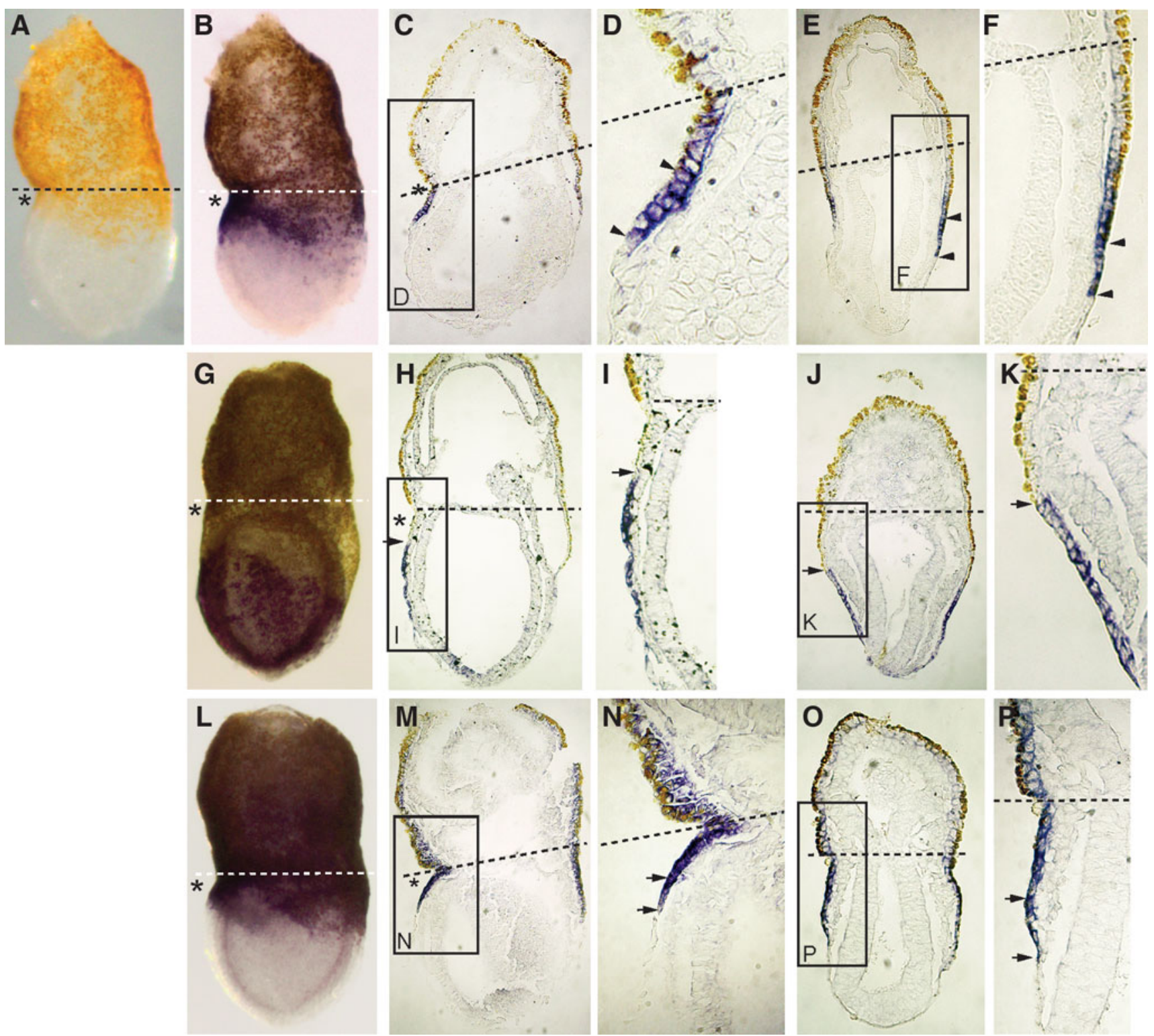

FIG. 4. Colocalization of 3,3'-diaminobenzidine (DAB)-stained visceral endoderm and $\operatorname{Spink}^{+} / \mathrm{Ttr}^{+} / \mathrm{Trh}^{+}$endoderm in E7.5 embryos. E7.5 mouse embryo showing the distribution of DAB ${ }^{+}$endoderm alone (A) and colocalization of $\mathrm{DAB}^{+}$and Spink $3^{+}$endoderm (B). Sagittal (C, D) and coronal (E, F) sections of a double stained E7.5 mouse embryo. The position of Spink ${ }^{+}$DAB $^{-}$cells is bracketed by arrowheads in D and F. An E7.5 mouse embryo showing the colocalization of DAB ${ }^{+}$ and $\mathrm{Trh}^{+}$endoderm in wholemount $(\mathbf{G})$, sagittal $(\mathbf{H}, \mathbf{I})$, and coronal $(\mathbf{J}, \mathbf{K})$ sections. The border between the $\operatorname{Trh}^{+}$cells and $\mathrm{DAB}^{+}$cells is indicated by the arrowheads. An E7.5 mouse embryo showing the colocalization of DAB ${ }^{+}$and Ttr $^{+}$endoderm in wholemount $(\mathbf{L})$, sagittal $(\mathbf{M}, \mathbf{N})$, and coronal $(\mathbf{O}, \mathbf{P})$ sections. The position of Ttr $^{+} \mathrm{DAB}^{-}$cells is bracketed by arrowheads in $\mathrm{N}$ and $\mathrm{P}$. The dashed line indicates the position of the embryonic and extra-embryonic boundary in all images. $*$ Anterior.

higher in EPLEBs cultured in KOSRM. Consistent with these data, Spink $3^{+}$and $\mathrm{Ttr}^{+}$cells were more prevalent in EPLEBs differentiated in SCM, whereas more $\operatorname{Trh}^{+}$cells were detected in EPLEBs differentiated in KOSRM (Fig. 6B). This analysis suggests that SCM and KOSRM support the formation of proximal and distal endoderm, but medium composition impacts the efficiency with which these populations form.

Acquisition of positional specification in other germ lineages can influence the repertoire of cell populations that can be formed during subsequent differentiation, and may influence the potential of the definitive endoderm populations formed in EPLEBs. EPLEBs differentiated for 5 days in
SCM or KOSRM were transferred to a SCM and allowed to differentiate for a further 10 days before they were analyzed for the expression of a panel of hepatic gene markers, (Fig. 6C) representing hepatoblasts (alpha-feto protein $[A f p]),{ }^{37}$ hepatocytes (carbamoyl-phosphate synthetase 1 [Cps 1), glucose-6-phosphatase, catalytic [G6pc], phosphoenolpyruvate carboxykinase $1[P c k 1]$, and tyrosine aminotransferase [Tat]), ${ }^{38,39}$ mature liver (cytochrome P450, family 7 , subfamily a, polypeptide 1 [Cyp $7 a 1]),{ }^{40}$ and general hepatic marker, albumin $(A l b) .^{41}$ Hepatic genes were chosen as the expression pattern of Spink3 included the lip and the lateral walls of the exposed regions of the foregut, the region of the embryo 

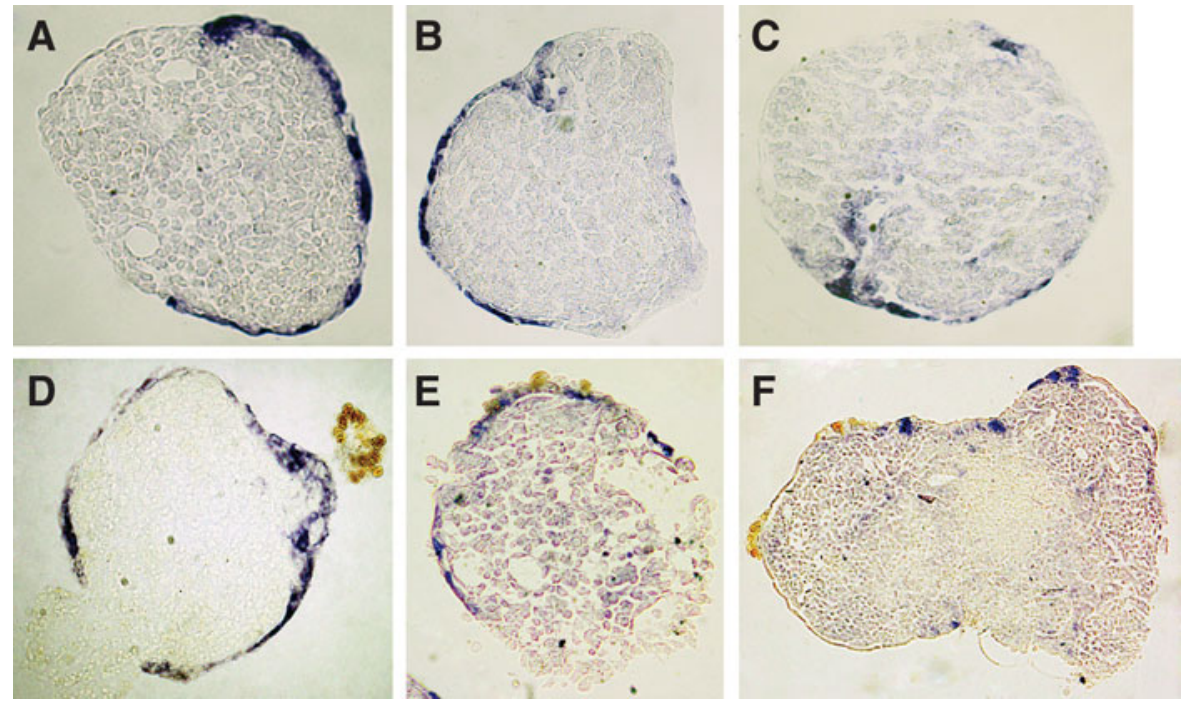

FIG. 5. Spink $3^{+}, T t r^{+}$, and $T r h^{+}$ endoderm cells that are not DABstained in EPLEBs resemble definitive endoderm. Typical EPLEBs showing the lack of $\mathrm{DAB}^{+}$cells (brown) and presence of Spink3 ${ }^{+}$ (A), $\operatorname{Ttr}^{+}$(B), and $\operatorname{Trh}^{+}$(C) cells. $\mathrm{DAB}^{+}$cells (brown) are detected on the surface of rare EPLEBs within a population: Spink $3^{+} \mathrm{DAB}^{-}$ (D), $T t r^{+} \mathrm{DAB}^{-}$(E), and $T r h^{+}$

$\mathrm{DAB}^{-}(\mathbf{F})$ endoderm cells resemble definitive endoderm while Spink3 ${ }^{-} \mathrm{DAB}^{+}$, Ttr $^{+} \mathrm{DAB}^{+}(\mathbf{E})$, and $\operatorname{Trh}^{-} \mathrm{DAB}^{+}(\mathbf{F})$ show a cuboidal morphology and represent visceral endoderm.
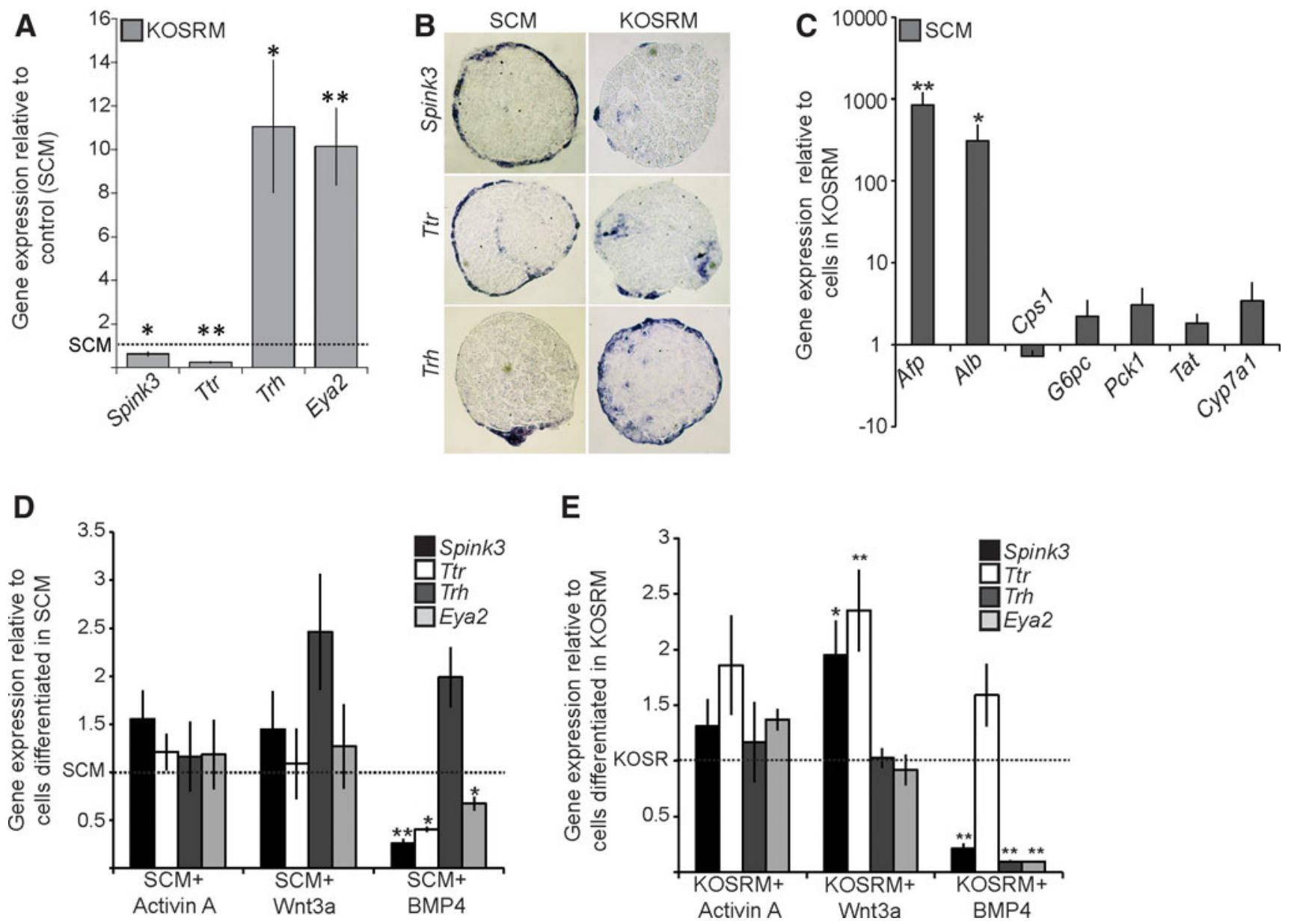

FIG. 6. Enrichment of proximal and distal definitive endoderm in EPLEBs. (A) Expression of proximal and distal definitive endoderm gene markers in EPLEBs cultured in KnockOut ${ }^{\mathrm{TM}}$ Serum Replacement-containing medium (KOSRM) relative to expression in EPLEBs cultured in serum-containing medium (SCM) by quantitative polymerase chain reaction (qPCR). Gene expression was normalized to $\beta$-actin. Error bars represent standard error of the mean; $n=7$. * Represents a significant change in gene expression when $p \leq 0.05$. (B) WISH analysis of the distribution of Spink3, Ttr and Trh transcripts in EPLEBs cultured in SCM or KOSRM, as indicated in the figure. (C) EPLEBs differentiated in SCM or KOSRM for 5 days were transferred to SCM and allowed to differentiate for a further 10 days before analysis for a panel of liver markers by qPCR. Gene expression was normalized to $\beta$-actin and expression in EPLEBs initially cultured in SCM has been expressed relative to EPLEBs initially cultured in KOSRM. Error bars represent standard error of the mean; $n=3$, a significant change in gene expression is denoted as * when the $p$-value is $\leq 0.05$ and $* *$ when $\leq 0.01$. (D-E) Effects of Activin A, Wnt3a and BMP4 on markers of definitive endoderm in EPLEBs cultured in SCM (C) or KOSRM (D) by qPCR. Gene expression was normalized to $\beta$-actin and fold change in gene expression is shown relative to SCM or KOSRM controls. Error bars represent standard error of the mean; $n=3(n=6 \mathrm{KOSRM}+\mathrm{Wnt} 3 \mathrm{a})$. A significant change in gene expression is denoted as * when the $p$-value is $<0.05$ and $* *$ when $<0.01$. 
containing the liver progenitors at this stage of development, ${ }^{42}$ and Spink3 was expressed in the liver bud of the E9.5 embryo (Fig. 3), making it likely that Spink3-expressing endoderm will form liver. The expression of $A f p$ and $A l b$ was significantly greater in derivatives of EPLEBs that had been initially cultured in SCM compared to those initially cultured in KOSRM (850and 300-fold, respectively). Consistent with this, Alb expression, detected as GFP expression in a cell line stably transfected with GFP under the control of the albumin promoter, was seen in approximately $10 \%$ EPLEBs differentiated in serum (Supplementary Fig. S3). These observations are consistent with a difference in potency between definitive endoderm formed from EPL cells in SCM and KOSRM, and they suggest that definitive endoderm formed on EPLEBs in SCM, defined as Spink $^{+} \mathrm{Ttr}^{+}$proximal definitive endoderm, was more likely to differentiate to early liver progenitors.

The ability of BMP4, Wnt3a, and Activin A to enrich for distal $\left(\mathrm{Trh}^{+}, \mathrm{Eya2}^{+}\right)$and proximal $\left(\operatorname{Spink}^{+}, \mathrm{Ttr}^{+}\right)$definitive endoderm in the presence or absence of serum was investigated. Evidence from genetic studies in mice have implicated these factors in the formation of the primitive streak and definitive endoderm. ${ }^{3,4,43,44}$ These factors have also been shown to be able to influence the expression of definitive endoderm markers during in vitro differentiation. ${ }^{26,45-48}$ EPLEBs were formed in SCM or KOSRM and the medium was supplemented after $24 \mathrm{~h}$ with Activin A, Wnt3a, or BMP4. On day 5 aggregates were analyzed for the expression of the definitive endoderm markers by qPCR (Fig. 6D, E). The addition of Activin A had surprisingly little effect on the amount of endoderm formed or the distribution of endoderm between the proximal and distal populations. Addition of Wnt3a to EPLEBs cultured in KOSRM, a medium that enhanced the formation of distal definitive endoderm, increased the expression of Spink3 and Ttr. The addition of BMP4 resulted in the reduction of endoderm marker expression, although expression of Trh and Ttr was maintained in SCM and KOSRM, respectively. Maintenance of some markers when BMP4 is added suggests that the formation of endoderm was reduced by not lost.

\section{Discussion}

Unlike EBs, which contain lineages derived from the three primary germ layers and the extra-embryonic endoderm, EPLEBs represent a much simpler in vitro differentiation paradigm that comprises essentially two lineages, mesoderm and definitive endoderm. ${ }^{16,17}$ The reduced complexity of EPL cell differentiation allowed the identification of genes expressed in cell populations that emerge from the primitive streak, and which include nascent definitive endoderm. Of the markers selected from the microarray data, four showed expression in the definitive endoderm layer of EPLEBs and in the endoderm of embryos, but expression was limited to the endoderm for Spink3 and Ttr only; Amot and Tgfblil transcripts were detected in the inner, mesoderm, population of EPLEBs and in mesoderm derivatives in the embryo. The expression pattern of Amot and Tgfblil in EPLEBs mirrored that of the commonly used endoderm marker Foxa2, which was also detected in the definitive endoderm and the mesoderm.

The expression of Ttr and Amot is not restricted to the embryonic portion of the egg cylinder embryo and expression of these genes is widespread in the visceral endoderm. ${ }^{2,49}$ The expression of these genes in the products of molecular gas- trulation in EPLEBs raises the potential that they are expressed in the definitive endoderm. ${ }^{16}$ In mouse, the position of the amnion has been used as a morphological landmark in E7.5 mouse embryos to delineate the boundary of the embryonic and extra-embryonic compartments of an embryo. ${ }^{32,50}$ The expression domains of Ttr, and Amot extend below the amnion into the proximal one third of embryonic region in E7.5 mouse embryos, ${ }^{2,15,33,49}$ a region that could be considered to contain definitive endoderm. Alternatively, this region could be populated with a mixed population comprising visceral and definitive endoderm. Double staining E7.5 mouse embryos with Spink3 or Ttr and a marker of endocytosis (DAB) has shown the interspersal of $\mathrm{DAB}^{+}$Spink $3^{+}$and $\mathrm{DAB}^{+}$Ttr $^{+}$ visceral endoderm with $\mathrm{DAB}^{-}$Spink $3^{+}$and $\mathrm{DAB}^{-}$Ttr $^{+}$definitive endoderm in the proximal embryonic region.

The expression of Spink3 and Ttr in the embryo, in combination with the expression of a characterized marker of the definitive endoderm, Trh, and the endocytotic ability of cells, reveals the complexity of the endoderm during gastrulation and defines three distinct regions: the $\mathrm{Trh}^{-} \mathrm{Ttr}^{+}$ Spink3 ${ }^{-} \mathrm{DAB}^{+}$extra-embryonic endoderm, the $\mathrm{Trh}^{+} \mathrm{Ttr}^{-}$ Spink $3^{-} \mathrm{DAB}^{-}$distal definitive endoderm, and a region of endoderm separating the two populations. Endoderm-separating extra-embryonic endoderm and distal endoderm comprises extra-embryonic endoderm that can endocytose proteins and expresses Spink3 and/or Ttr but not Trh, and a genetically distinct definitive endoderm population that is $\mathrm{DAB}^{-}$ and expresses Spink3. Distinct subsets of definitive endoderm with different developmental potential have been identified by fate mapping ${ }^{1,7-9}$ and mapping the pathways that regulate endoderm formation. ${ }^{51}$ Tracing the developmental progress of cells from the anterior proximal region showed that they contributed to the anterior endoderm along the yolk sac-embryo boundary, ventral foregut endoderm caudal to the heart, and the lip of the foregut opening. ${ }^{8,9}$ Cells in the proximal posterior region were allocated to the lateral region of the posterior gut. ${ }^{8,9}$ The allocation of cells from the proximal endoderm into embryonic tissues supports the hypothesis that a proportion of the cells in this region are definitive endoderm. The contribution of cells from this region to extra-embryonic structures ${ }^{9}$ could result from the presence of visceral endoderm cells within the population. The diversity of outcomes arising from fate-mapping this area is, therefore, consistent with the mixed cell population identified genetically here. The later distribution of Spink3-expressing tissues is closely aligned with those tissues identified by fate-mapping to originate from the proximal embryonic region, reflecting the expression of Spink3 in both populations of endoderm present within this region. The restricted expression of Spink3 in the proximal definitive endoderm population provides a valuable tool that can be used to further investigation the molecular mechanisms regulating the formation and morphogenesis of endoderm in vivo and to define, enrich, and isolate positionally specified endoderm populations from pluripotent cells in culture.

The definitive endoderm can be subdivided into proximal and distal regions on the basis of Spink3 and Trh expression, respectively. Populations expressing these markers can be detected on the surface of EPLEBs suggesting that both populations can arise during in vitro differentiation. To date, little attention has been paid to the positional specification of the definitive endoderm in culture, reflected in a single report 
that describes the formation of anterior definitive endoderm in culture. ${ }^{52}$ Selective enrichment for proximal and distal populations was achieved through the use of alternate culture conditions, with EPLEBs cultured in serum preferentially forming Spink $3^{+}$proximal definitive endoderm and those cultured in serum replacement enriched in $\mathrm{Trh}^{+}$distal definitive endoderm. Enrichment was reflected in differential expression of early liver progenitor markers $A f p$ and $A l b$ by cell populations derived from EPLEBs initially differentiated in serum and serum replacement, with those exposed to serum expressing significantly higher levels of these genes. Differentiation in the culture system used did not appear to promote the further maturation of these cells to hepatocytes or mature liver; the consistent expression of hepatocyte markers and markers of mature liver was also not seen in EBs (Supplementary Fig. S4). These data are consistent with proximal and distal definitive endoderm having distinct differentiation potentials in culture.

The ability of culture conditions to regulate the formation of proximal and distal definitive endoderm suggests that the system will be responsive to the addition of growth factors. Activin A has been shown to enrich the formation of definitive endoderm from mouse $26,45,46,48,52,53$ and human ES cells ${ }^{47,54}$ and from EPL cells. ${ }^{16}$ Likewise, Wnt signaling has been shown to induce molecular gastrulation and the subsequent formation of the definitive endoderm. ${ }^{48,55-58}$ The addition of Activin A did not change the expression of the positionally expressed endoderm markers or increase the formation of definitive endoderm in differentiating EPLEBs. The differentiation system did respond to growth factor addition, evidenced by the differences in marker expression between cells differentiated in the presence of BMP4 or Wnt3a and the controls. Potentially, the ability of Activin A to induce definitive endoderm relies on the presence of additional factors not present within the medium or within the EPLEB differentiation system. To maximize endoderm formation from ES cells, differentiation systems have been developed that couple Activin A with Wnt3a. The inhibition of BMP4 has been shown to improve yields of definitive endoderm during ES cell differentiation; BMP4 inhibition is thought to favor the formation of anterior primitive streak and derivatives over posterior streak derivatives. ${ }^{59}$ The observed reduction in definitive endoderm marker expression when BMP4 is present could reflect the bias of differentiation towards posterior outcomes.

There are several endoderm-derived cell populations with potential applications in commercial and clinical research, including hepatocytes, lung epithelium, and insulin-secreting pancreatic cells, if they could be sourced in sufficient quantity, quality, and purity. One potential source of these cells is through the differentiation of human pluripotent cells in culture. To date, the formation of these cells from ES cells has been difficult to optimize with the result that the frequency of the desired cell type can be too low for commercial or clinical use. One approach to resolving this problem is to optimize the initial derivation of an enriched population of definitive endoderm that can be used as a substrate for further differentiation. The work presented here suggests that it is not simply the enrichment of definitive endoderm that is required but and understanding and tailoring of protocols that enrich for an appropriately specified population that should be the goal.

\section{Acknowledgments}

The authors thank Patrick Tam and Vanessa Jones (Children's Medical Research Institute, Westmead, NSW, Australia) for advice on the processing of embryos, Don Newgreen (Murdoch Childrens Research Institute, Parkville, VIC, Australia) for help with the identification of anatomical landmarks in embryo sections, Gary Quinn (National Cancer Centre Research Institute, Japan) for the pALB-GFP construct, and Marilyn Renfree (Department of Zoology, University of Melbourne, Victoria, Australia) for insightful discussion of this work. Also, the authors thank members of the Rathjen and Renfree groups for technical assistance and critical evaluation of the approaches used here. H.N.G. was supported by Australian Postgraduate Award. The preparation of this paper was supported by an Albert Shimmins Postgraduate Writing-up Award from the Faculty of Science, University of Melbourne. This work was supported by the University of Melbourne.

\section{Author Disclosure Statement}

No competing financial interests exist.

\section{References}

1. Tam PP, Khoo PL, Lewis SL, et al. Sequential allocation and global pattern of movement of the definitive endoderm in the mouse embryo during gastrulation. Development. 2007; 134:251-260.

2. Kwon GS, Viotti M, Hadjantonakis AK. The endoderm of the mouse embryo arises by dynamic widespread intercalation of embryonic and extraembryonic lineages. Dev Cell. 2008;15:509-520.

3. Conlon FL, Lyons KM, Takaesu N, et al. A primary requirement for nodal in the formation and maintenance of the primitive streak in the mouse. Development. 1994;120:1919-1928.

4. Vincent SD, Dunn NR, Hayashi S, et al. Cell fate decisions within the mouse organizer are governed by graded Nodal signals. Genes Dev. 2003;17:1646-1662.

5. Lowe LA, Yamada S, Kuehn MR. Genetic dissection of nodal function in patterning the mouse embryo. Development. 2001;128:1831-1843.

6. Norris DP, Brennan J, Bikoff EK, et al. The Foxh1-dependent autoregulatory enhancer controls the level of Nodal signals in the mouse embryo. Development. 2002;129:3455-3468.

7. Lawson KA, Pedersen RA. Cell fate, morphogenetic movement and population kinetics of embryonic endoderm at the time of germ layer formation in the mouse. Development. 1987;101:627-652.

8. Lawson KA, Meneses JJ, Pedersen RA. Cell fate and cell lineage in the endoderm of the presomite mouse embryo, studied with an intracellular tracer. Dev Biol. 1986;115:325-339.

9. Tam PP, Khoo PL, Wong N, et al. Regionalization of cell fates and cell movement in the endoderm of the mouse gastrula and the impact of loss of Lhxl(Liml) function. Dev Biol. 2004;274:171-187.

10. Wells JM, Melton DA. Vertebrate endoderm development. Annu Rev Cell Dev Biol. 1999;15:393-410.

11. Grapin-Botton A. Endoderm specification. In: StemBook. Cambridge, MA: Harvard Stem Cell Institute, 2008. Available at: http://www.ncbi.nlm.nih.gov/books/NBK27052/

12. Zorn AM, Wells JM. Vertebrate endoderm development and organ formation. Annu Rev Cell Dev Biol. 2009;25: 221-251. 
13. McKnight KD, Hou J, Hoodless PA. Dynamic expression of thyrotropin-releasing hormone in the mouse definitive endoderm. Dev Dyn. 2007;236:2909-2917.

14. Gu G, Wells JM, Dombkowski D, et al. Global expression analysis of gene regulatory pathways during endocrine pancreatic development. Development. 2004;131:165-179.

15. Moore-Scott BA, Opoka R, Lin SC, et al. Identification of molecular markers that are expressed in discrete anteriorposterior domains of the endoderm from the gastrula stage to mid-gestation. Dev Dyn. 2007;236:1997-2003.

16. Vassilieva S, Goh HN, Lau KX, et al. A system to enrich for primitive streak-derivatives, definitive endoderm and mesoderm, from pluripotent cells in culture. PLoS One 2012;7: e38645.

17. Lake J, Rathjen J, Remiszewski J, et al. Reversible programming of pluripotent cell differentiation. J Cell Sci. 2000; 113(Pt 3):555-566.

18. Doetschman TC, Eistetter H, Katz M, et al. The in vitro development of blastocyst-derived embryonic stem cell lines: formation of visceral yolk sac, blood islands and myocardium. J Embryol Exp Morphol. 1985;87:27-45.

19. Rathjen J, Rathjen PD. Lineage specific differentiation of mouse ES cells: formation and differentiation of early primitive ectoderm-like (EPL) cells. Methods Enzymol. 2003;365:3-25.

20. Yamamoto Y, Teratani T, Yamamoto H, et al. Recapitulation of in vivo gene expression during hepatic differentiation from murine embryonic stem cells. Hepatology. 2005; 42:558-567.

21. Muller PY, Janovjak H, Miserez AR, et al. Processing of gene expression data generated by quantitative real-time RT-PCR. Biotechniques. 2002;32:1372-1374, 1376, 13781379.

22. Simon P. Q-Gene: processing quantitative real-time RTPCR data. Bioinformatics. 2003;19:1439-1440.

23. Rosen B, Beddington RS. Whole-mount in situ hybridization in the mouse embryo: gene expression in three dimensions. Trends Genet. 1993;9:162-167.

24. Kanai-Azuma M, Kanai Y, Gad JM, et al. Depletion of definitive gut endoderm in Sox17-null mutant mice. Development. 2002;129:2367-2379.

25. Coucouvanis E, Martin GR. Signals for death and survival: a two-step mechanism for cavitation in the vertebrate embryo. Cell. 1995;83:279-287.

26. Kubo A, Shinozaki K, Shannon JM, et al. Development of definitive endoderm from embryonic stem cells in culture. Development. 2004;131:1651-1662.

27. Soudais C, Bielinska M, Heikinheimo M, et al. Targeted mutagenesis of the transcription factor GATA-4 gene in mouse embryonic stem cells disrupts visceral endoderm differentiation in vitro. Development. 1995;121:3877-88.

28. Bernardo AS, Faial T, Gardner L, et al. BRACHYURY and CDX2 mediate BMP-induced differentiation of human and mouse pluripotent stem cells into embryonic and extraembryonic lineages. Cell Stem Cell. 2011;9:144-155.

29. Rathjen J, Haines BP, Hudson KM, et al. Directed differentiation of pluripotent cells to neural lineages: homogeneous formation and differentiation of a neurectoderm population. Development 2002;129:2649-2661.

30. Monaghan AP, Kaestner KH, Grau E, et al. Postimplantation expression patterns indicate a role for the mouse forkhead/ HNF-3 alpha, beta and gamma genes in determination of the definitive endoderm, chordamesoderm and neuroectoderm. Development. 1993;119:567-578.
31. Batten BE, Haar JL. Fine structural differentiation of germ layers in the mouse at the time of mesoderm formation. Anat Rec. 1979;194:125-141.

32. Tam PP, Williams EA, Chan WY. Gastrulation in the mouse embryo: ultrastructural and molecular aspects of germ layer morphogenesis. Microsc Res Tech. 1993;26: 301-328.

33. Shimono A, Behringer RR. Angiomotin regulates visceral endoderm movements during mouse embryogenesis. Curr Biol. 2003;13:613-617.

34. Chen WS, Manova K, Weinstein DC, et al. Disruption of the HNF-4 gene, expressed in visceral endoderm, leads to cell death in embryonic ectoderm and impaired gastrulation of mouse embryos. Genes Dev. 1994;8:2466-2477.

35. Maurer ME, Cooper JA. Endocytosis of megalin by visceral endoderm cells requires the Dab2 adaptor protein. J Cell Sci. 2005;118:5345-5355.

36. Kadokawa Y, Kato Y, Eguchi G. Cell lineage analysis of the primitive and visceral endoderm of mouse embryos cultured in vitro. Cell Differ. 1987;21:69-76.

37. Fausto N, Lemire JM, Shiojiri N. Cell lineages in hepatic development and the identification of progenitor cells in normal and injured liver. In: Proceedings of the Society for Experimental Biology and Medicine. Society for Experimental Biology and Medicine. Royal Society of Medicine; pp. 237-241; 1993.

38. Hirose Y, Itoh T, Miyajima A. Hedgehog signal activation coordinates proliferation and differentiation of fetal liver progenitor cells. Exp Cell Res. 2009;315:26482657.

39. Kamiya A, Kinoshita T, Ito Y, et al. Fetal liver development requires a paracrine action of oncostatin $M$ through the gp130 signal transducer. EMBO J 1999;18:2127-2136.

40. Tanimizu N, Miyajima A. Molecular mechanism of liver development and regeneration. Int Rev Cytol. 2007;259: $1-48$.

41. Hay DC, Zhao D, Fletcher J, et al. Efficient differentiation of hepatocytes from human embryonic stem cells exhibiting markers recapitulating liver development in vivo. Stem Cells. 2008;26:894-902.

42. Tremblay KD, Hoodless PA, Bikoff EK, et al. Formation of the definitive endoderm in mouse is a Smad2-dependent process. Development. 2000;127:3079-3090.

43. Liu P, Wakamiya M, Shea MJ, et al. Requirement for Wnt3 in vertebrate axis formation. Nat Genet 1999;22: 361-365.

44. Winnier G, Blessing M, Labosky PA, et al. Bone morphogenetic protein-4 is required for mesoderm formation and patterning in the mouse. Genes Dev. 1995;9:2105-2116.

45. Tada S, Era T, Furusawa C, et al. Characterization of mesendoderm: a diverging point of the definitive endoderm and mesoderm in embryonic stem cell differentiation culture. Development. 2005;132:4363-4374.

46. Yasunaga M, Tada S, Torikai-Nishikawa S, et al. Induction and monitoring of definitive and visceral endoderm differentiation of mouse ES cells. Nat Biotechnol 2005;23: $1542-1550$.

47. D'Amour KA, Agulnick AD, Eliazer S, et al. Efficient differentiation of human embryonic stem cells to definitive endoderm. Nat Biotechnol. 2005;23:1534-1541.

48. Gadue P, Huber TL, Paddison PJ, et al. Wnt and TGF-beta signaling are required for the induction of an in vitro model of primitive streak formation using embryonic stem cells. Proc Natl Acad Sci U S A. 2006;103:16806-16811. 
49. Kwon GS, Hadjantonakis AK. Transthyretin mouse transgenes direct RFP expression or Cre-mediated recombination throughout the visceral endoderm. Genesis. 2009;47: 447-455.

50. Downs KM, Davies T. Staging of gastrulating mouse embryos by morphological landmarks in the dissecting microscope. Development. 1993;118:1255-1266.

51. Yap C, Goh HN, Familari M, et al. The formation of proximal and distal definitive endoderm populatiosn in culture requires p38 MAPK activity. J Cell Sci. 2014; in press.

52. Morrison GM, Oikonomopoulou I, Migueles RP, et al. Anterior definitive endoderm from ESCs reveals a role for FGF signaling. Cell Stem Cell. 2008;3:402-415.

53. Takenaga M, Fukumoto M, Hori Y. Regulated Nodal signaling promotes differentiation of the definitive endoderm and mesoderm from ES cells. J Cell Sci. 2007;120: 2078-2090.

54. McLean AB, D'Amour KA, Jones KL, et al. Activin a efficiently specifies definitive endoderm from human embryonic stem cells only when phosphatidylinositol 3-kinase signaling is suppressed. Stem Cells. 2007;25: 29-38.

55. Bone HK, Nelson AS, Goldring CE, et al. A novel chemically directed route for the generation of definitive endoderm from human embryonic stem cells based on inhibition of GSK-3. J Cell Sci. 2011;124:1992-2000.

56. Lindsley RC, Gill JG, Kyba M, et al. Canonical Wnt signaling is required for development of embryonic stem cell-derived mesoderm. Development. 2006;133:37873796.

57. Dravid G, Ye Z, Hammond H, et al. Defining the role of Wnt/beta-catenin signaling in the survival, proliferation, and self-renewal of human embryonic stem cells. Stem Cells 2005;23:1489-1501.

58. Nakanishi M, Kurisaki A, Hayashi Y, et al. Directed induction of anterior and posterior primitive streak by Wnt from embryonic stem cells cultured in a chemically defined serum-free medium. FASEB J. 2009;23:114-122.
59. Li F, He Z, Li Y, et al. Combined activin A/LiCl/Noggin treatment improves production of mouse embryonic stem cell-derived definitive endoderm cells. J Cell Biochem. 2011;112:1022-1034.

Address correspondence to: Dr. Joy Rathjen Menzies Research Institute Tasmania 17 Liverpool Street Hobart, TAS 7000 Australia

E-mail: joy.rathjen@utas.edu.au

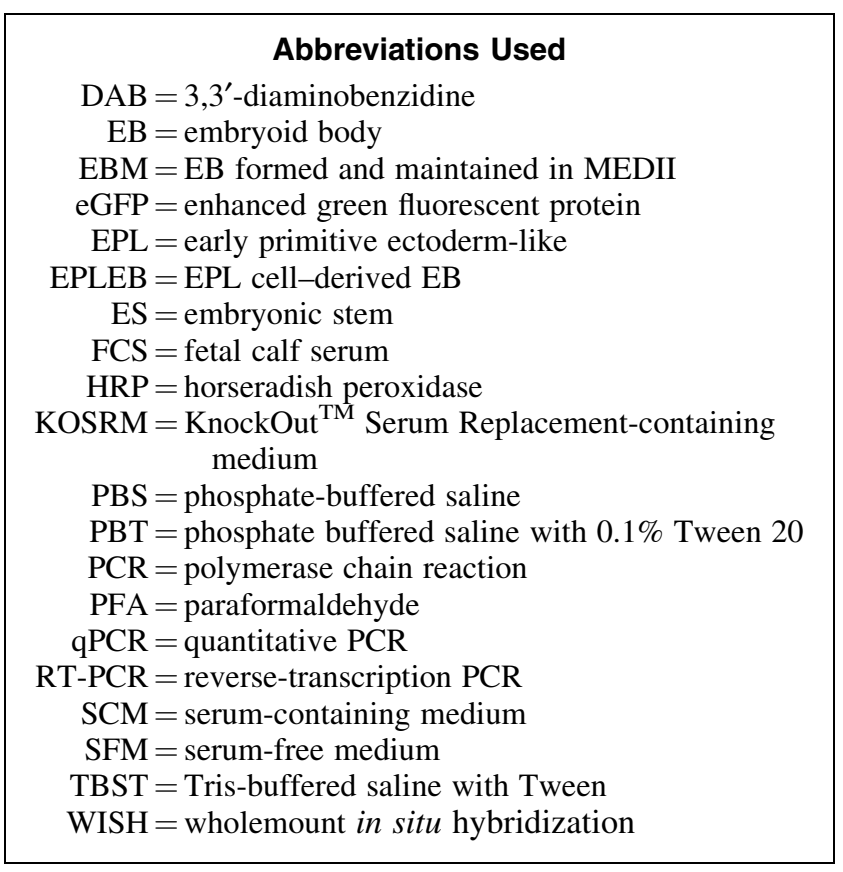

